at such times. I am inclined to think, however, that a more probable reason is to be found in the general conditions of the atmosphere preceding and during the storm. It has been found in our laboratory that bacteria growing on gelatine will multiply with unusual rapidity during warm, sultry weather. Now, these are the atmospheric conditions that usually precede and accompany thunder-storms. It seems to me most likely, therefore, that whatever rapid souring occurs is due to an unusually rapid growth of bacteria, caused by especially favorable conditions of the atmosphere.

The experience of the proprietor of a neighboring creamery confirms to a certain extent these conclusions. He finds, that, if milk is kept at a uniformly low temperature during the thunderstorm season, no trouble results from rapid souring, indicating that this souring, when it occurs, is due more to a high temperature and sultry atmosphere than to the ozone in the air. If this were a process of direct oxidation, it should take place, partially at least, at the lower temperature.

Professor Tolomei finds, also, that a slight electric current, if less than three ampères, will have a preservative effect on milk, the current being passed directly through the liquid. A current greater than three ampères will decompose the milk.

In our experiments, a current of less than one-fortieth of an ampère was sufficient to produce decomposition, with a certain amount of coagulation at each electrode. A stronger current would produce complete coagulation, with the somewhat curious result that the coagulum was strongly acid at the positive pole, and more feebly alkaline at the negative pole.

Aaron L. Treadwell.

Wesleyan University,

Middletown, Conn., March 20.

\section{Mixed Races.}

DR. F. von Luschan, in his description of the Tachtadschy (Reisen in Lykien, etc., Vienna, 1889), calls attention to the important fact that the Greeks of Lycia represent a mixture of two distinct types, and from these facts draws the following inference: "At first glance, it appears remarkable and hardly probable that two disparate types should remain distinct, although intermarriage has continued without interruption through thousands of years. But we must acknowledge that it would be just as remarkable if continued intercrossing should result in the production of a middle type (Mischform). It is true that at the present time the greater number of anthropologists appear to be of the opinion that middle forms originate wherever two distinct ty pes live in close contact for a long time. If this is true at all, it is true only in a very limited sense, and still needs to be proven. A priori, we rather ought to expect that one or the other of these types would soon succumb in the struggle for existence. It would become extinct, and give way to the other type; or both types might continue to co-exist, although intercrossing might go on for centuries. They would undergo no other changes than those which each singly, uninfluenced by the other, would have undergone by the agency of physical causes." He exemplifies these opinions by statistical treatment of his cranial material, and by showing that in a single family all the extreme types which occur among the whole people are found.

Measurements of mixed Indian types give results which tally exactly with Dr. Von Luschan's views, and tend to support Kollmann's conclusions regarding the stability of cranial forms. The Bilqula (Bella Coola) of British Columbia are a mixed people, their language showing that they are of Salish affinity, while they have intermarried extensively with Athapascans and Haeltzukans. A study of the distribution of occurrence of length-width indices of their heads shows that the indices of from 79 to 81 are frequent, those about 83 rare, those of from 85 to 87 again very frequent. The first index corresponds to the most frequent one of the Haeltzukans; the last, to the most frequent one of the Athapascans of this region. If we consider the facial indices, a similar relation reveals itself. We find a greater frequency of the indices ranging about 79, a few cases ranging about 82 , and many about 85 . The beight of body shows the same character of distribution, - a maximum about 160 centimetres, and another about 168 centimetres. If the three curves of frequency are drawn out, their correspondence is found to be so close that it cannot be due to mere accident. Other measurements do not show the same peculiarity, because those of the peoples of the coast do not differ materially from those of the peoples of the interior.

When these same curves are drawn out for the Oregonian Athapascans, it appears that the curves are also alike among themselves, while they differ fundamentally from those of the Bilqula. I give here a table of the length-width indices of the heads of the Oregonian Athapascans, Northern Californians, and crosses between the two, which will be found instructive:-

\begin{tabular}{|c|c|c|c|c|c|c|c|c|c|c|c|c|c|c|}
\hline & $|75| r \mid$ & & $7|78|$ & 79 & $80 \mid 8$ & & & 84 & & & & 38 & & \\
\hline Oregonian Athapascans..... & 1 & 1 & & 2 & 5 & 5 & 55 & 5 & 9 & & $\begin{array}{lll}2 & 1\end{array}$ & $1 \mid 3$ & & 2 \\
\hline Crosses...$\ldots \ldots \ldots \ldots \ldots$ & - & & & 1 & 1 & - & & - & 1 & & & 1 & & - \\
\hline Northern Californians . &. & - & & 2 & 2 & 2 & 1 - & $-1-$ & - & - & & - & - & - \\
\hline
\end{tabular}

The first column shows particularly a much slower increase than we ought to expect if it represented a simple error curve; the second column shows a great variability, due to the presence of two distinct types. We see, notwithstanding the small number of cases, the maxima of the first and of the third columns clearly indicated. The asymmetry of the tirst column is easily explainable on the assumption of an intermixture with Californian tribes, and that therefore the indices peculiar to them occur more frequently.

On studying the single cases of these groups, it appears, that, although the characteristics of the component types become apparent by a statistical treatment of the series, they do not exist in the individual. The individuals are not representatives of one of the parent types, but mixed types; some parts of their bodies representing one type, other parts the other type. This mixture appears in a great variety of combinations. Middle types, that is, those standing between the two parent types, if found at all, are very few in number. Franz BOAS.

Clark University, Worcester, Mass., March 17.

\section{BOOK-REVIEWS.}

Outlines of Psychology. By Harald HöfFding. Tr. by Mary E. Lowndes. New York, Macmillan. 12. $\$ 1.50$.

THE translation of this work has not been made from the original Danish, but from the German translation. Professor Höffding, however, considers the German version a correct and adequate representation of the original, so that English readers can here obtain an accurate account of his views. The English version is natural and easy, and the author's meaning is, as a rule, plain and intelligible. The work is written with ability, and gives evidence of prolonged study of the subject in all its departments. It opens with some account of the scope and method of psychology, followed by a chapter on the relations of mind and body, and then takes up in succession the three fundamental elements of mental life,- cognition, feeling, and will,-the first of them naturally receiving the principal share of attention. The work is designed as a manual for students; but for that purpose the arrangement is bad, since the earlier chapters can hardly be understood without some previous knowledge of both psychology and philosophy. The plainness of the author's style, however, serves partly to remove this difficulty.

As regards the substance of the work, our judgment must be rather unfavorable. Professor Höffding's philosophical standpoint is that of the association school, modified somewhat by evolutionism, yet not differing essentially from that of the English writers with whom we are familiar. He attempts, indeed, to treat his subject without reference to philosophical theories, stating at the outset that psychology is a purely empirical science in no way dependent on metaphysics; yet he is not able to adhere to this position, but drops into philosophical discussion at intervals 